\title{
Heterogeneous Phase Transfer
}

\section{Catalysis In Solid Phase Syntheses}

\section{Of Anth-Cyclic Tetrapeptides}

Dongyue Xin ${ }^{1}$, Jian Yuan ${ }^{2}$, Kwok-Yin Wong ${ }^{2}$ and Kevin Burgess ${ }^{1 *}$

1 Department of Chemistry, Texas A \& M University, Box 30012, College Station, TX 77842, USA

${ }^{2}$ Department of Applied Biology and Chemical Technology and the State Key Laboratory of Chirosciences, The Hong Kong Polytechnic University, Hunghom, Kowloon, Hong Kong, P.R. China

E-mail: burgess@tamu.edu 


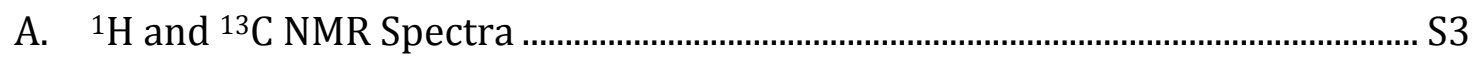

B. Optimization of the Synthesis of Linear Peptides ….............................................

C. Optimization of On-bead Cyclization ..........................................................................

D. HPLC Traces For Crude Cyclic Peptide Products Cleaved From The Resin ...S20 


\section{A. ${ }^{1} \mathrm{H}$ and ${ }^{13} \mathrm{C}$ NMR Spectra}

1-(3-(Methoxycarbonyl)-4-nitrophenyl)piperidine-4-carboxylic acid (2)<smiles>CC(=O)c1cc(N2CCC(C(=O)O)CC2)ccc1[N+](=O)[O-]</smiles>

${ }^{1} \mathrm{H}$ NMR

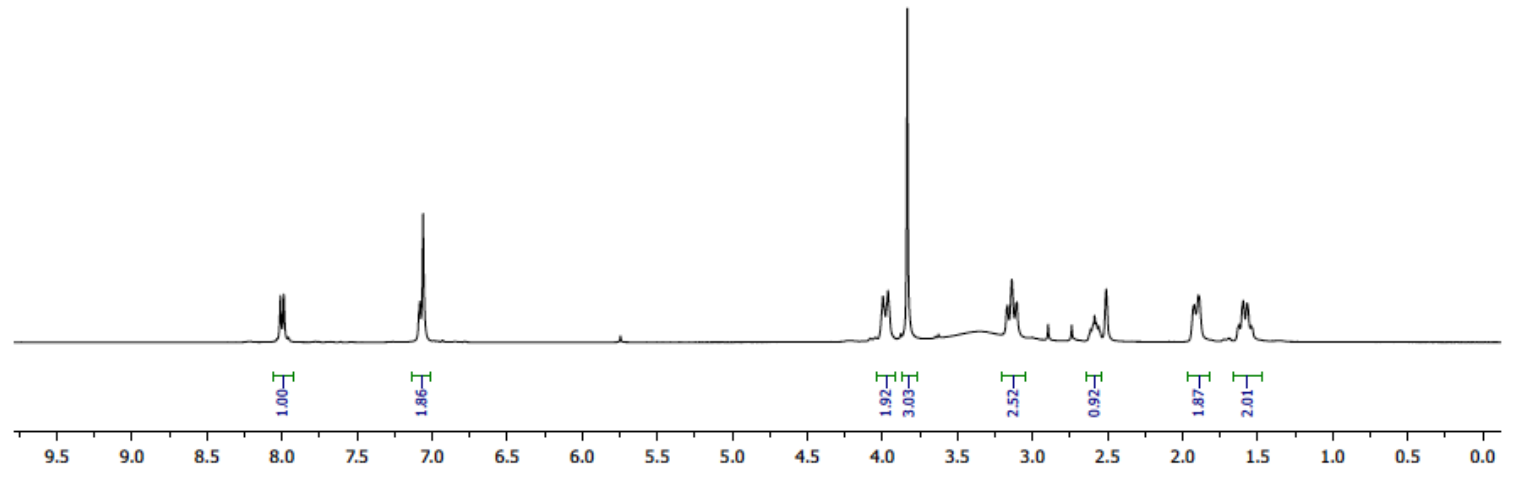

${ }^{13} \mathrm{C}$ NMR
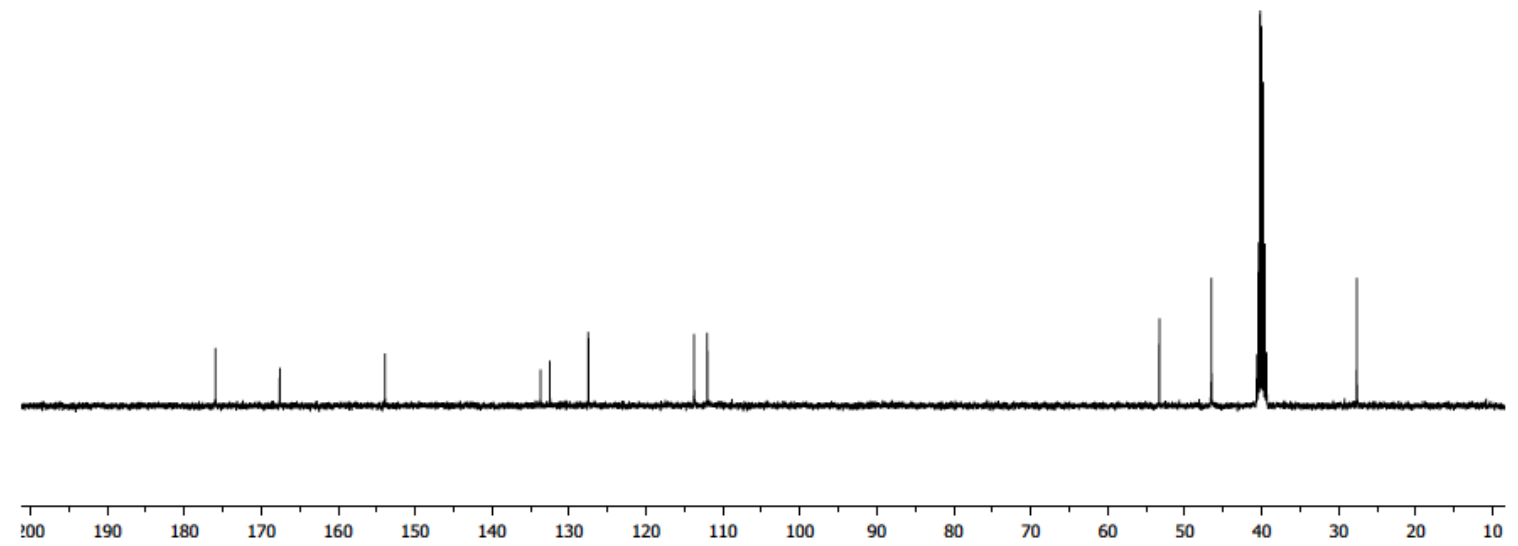
1-(4-((((9H-Fluoren-9-yl)methoxy)carbonyl)amino)-3-

(methoxycarbonyl)phenyl)piperidine-4-carboxylic acid (3)<smiles>C=Nc1ccc(N2CCC(C(=O)O)CC2)cc1C(=O)OC</smiles>

${ }^{1} \mathrm{H}$ NMR

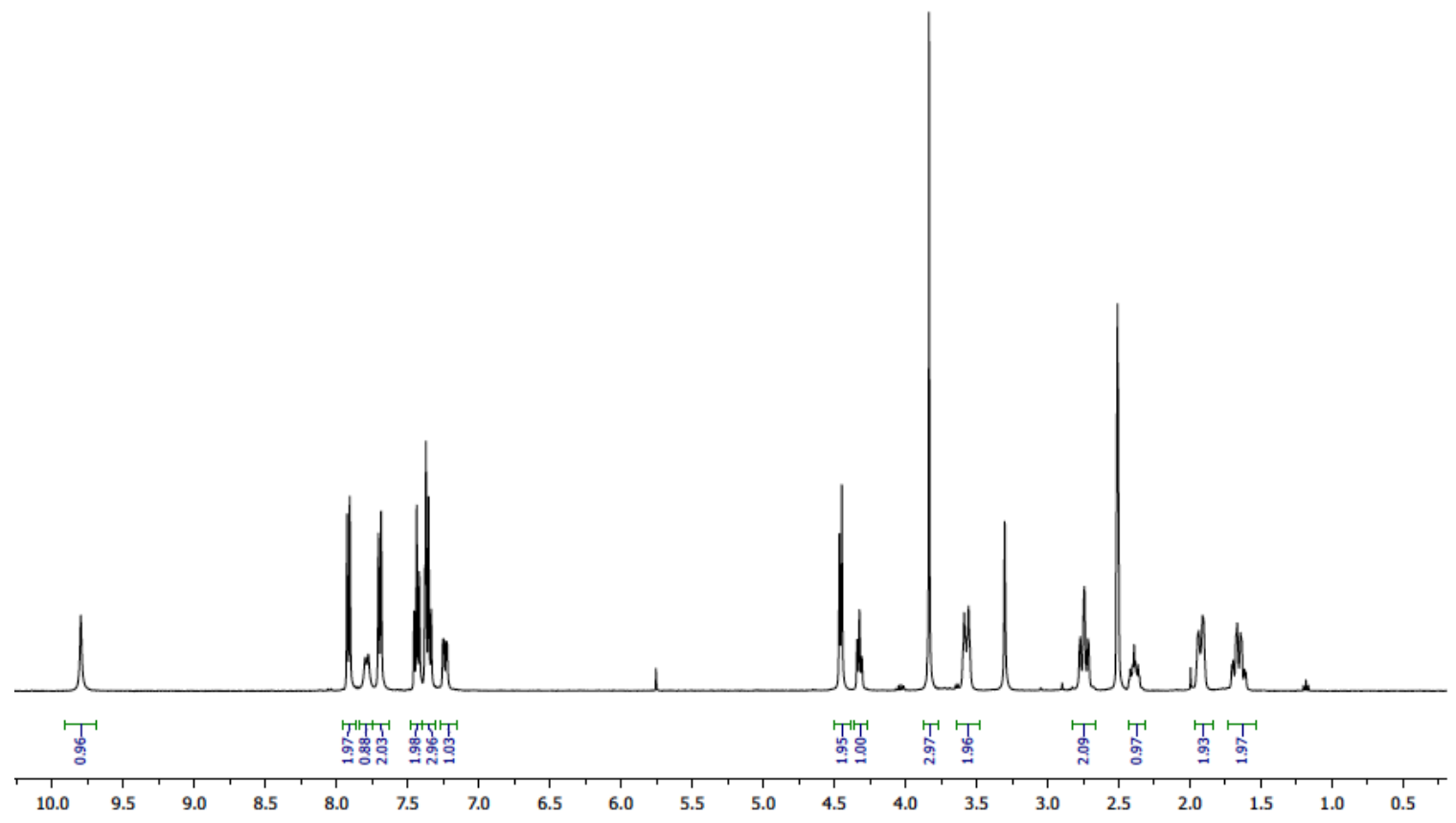




\section{${ }^{13} \mathrm{C} N M R$}
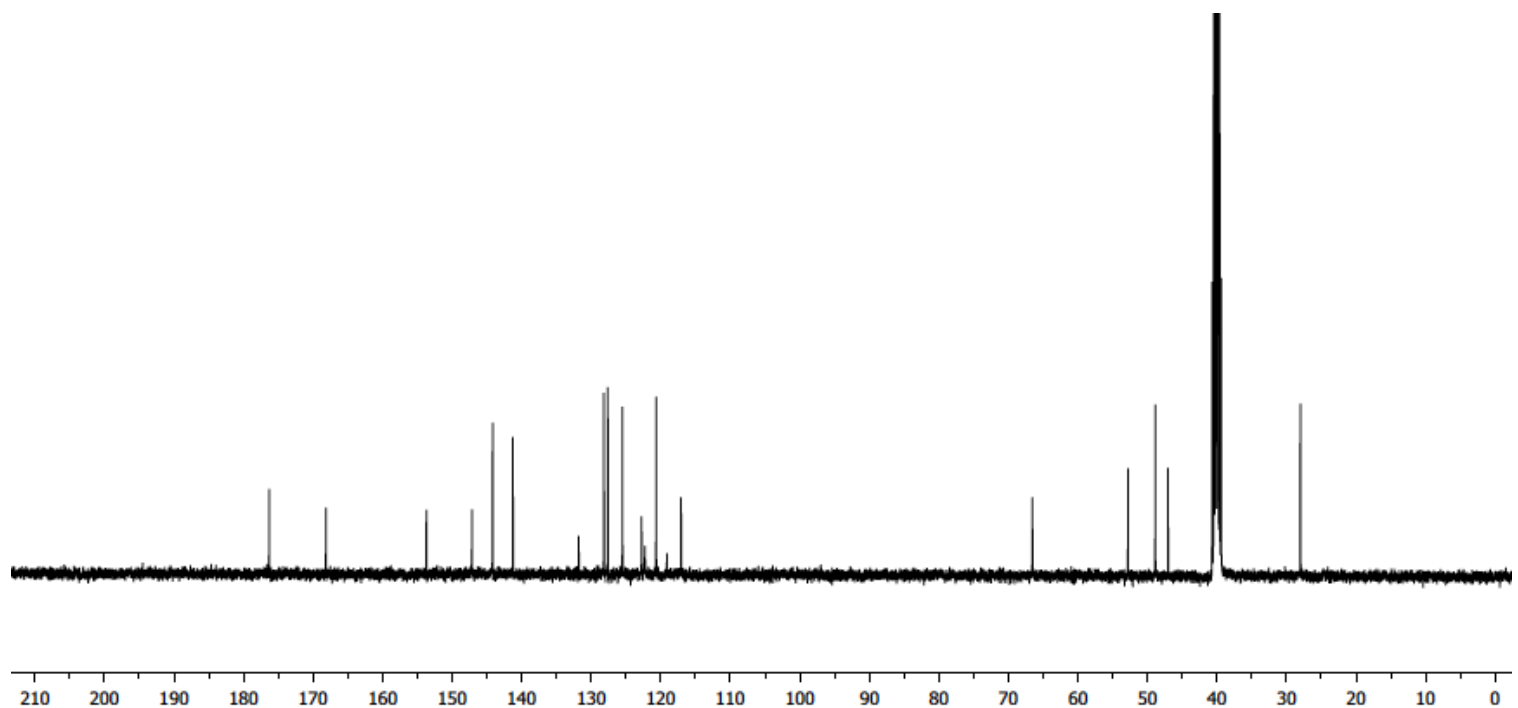

1-((3S,6S,9S)-3-(4-Hydroxybenzyl)-6-(hydroxymethyl)-9-isopropyl-2,5,8,11-

tetraoxo-2,3,4,5,6,7,8,9,10,11-decahydro-1Hbenzo $[k][1,4,7,10]$ tetraazacyclotridecin-13-yl)piperidine-4-carboxylic acid (LLL1vsy)<smiles>CC(C)[C@H]1NC(=O)c2cc(N3CCC(C(=O)O)CC3)ccc2NC(=O)[C@H](Cc2ccc(O)cc2)NC(=O)[C@H](CO)NC1=O</smiles> 
${ }^{1} \mathrm{H}$ NMR

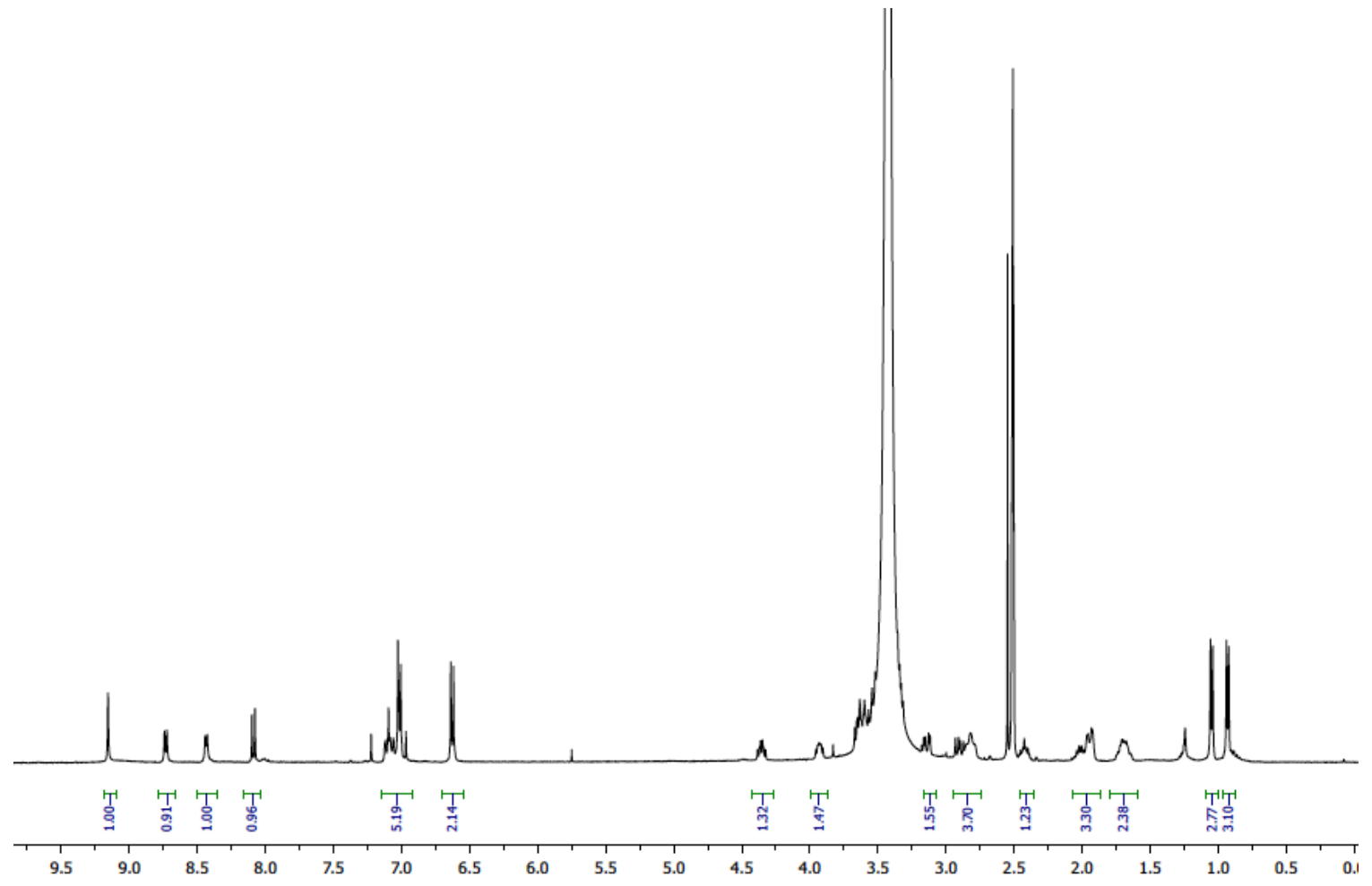

${ }^{13} \mathrm{C}$ NMR
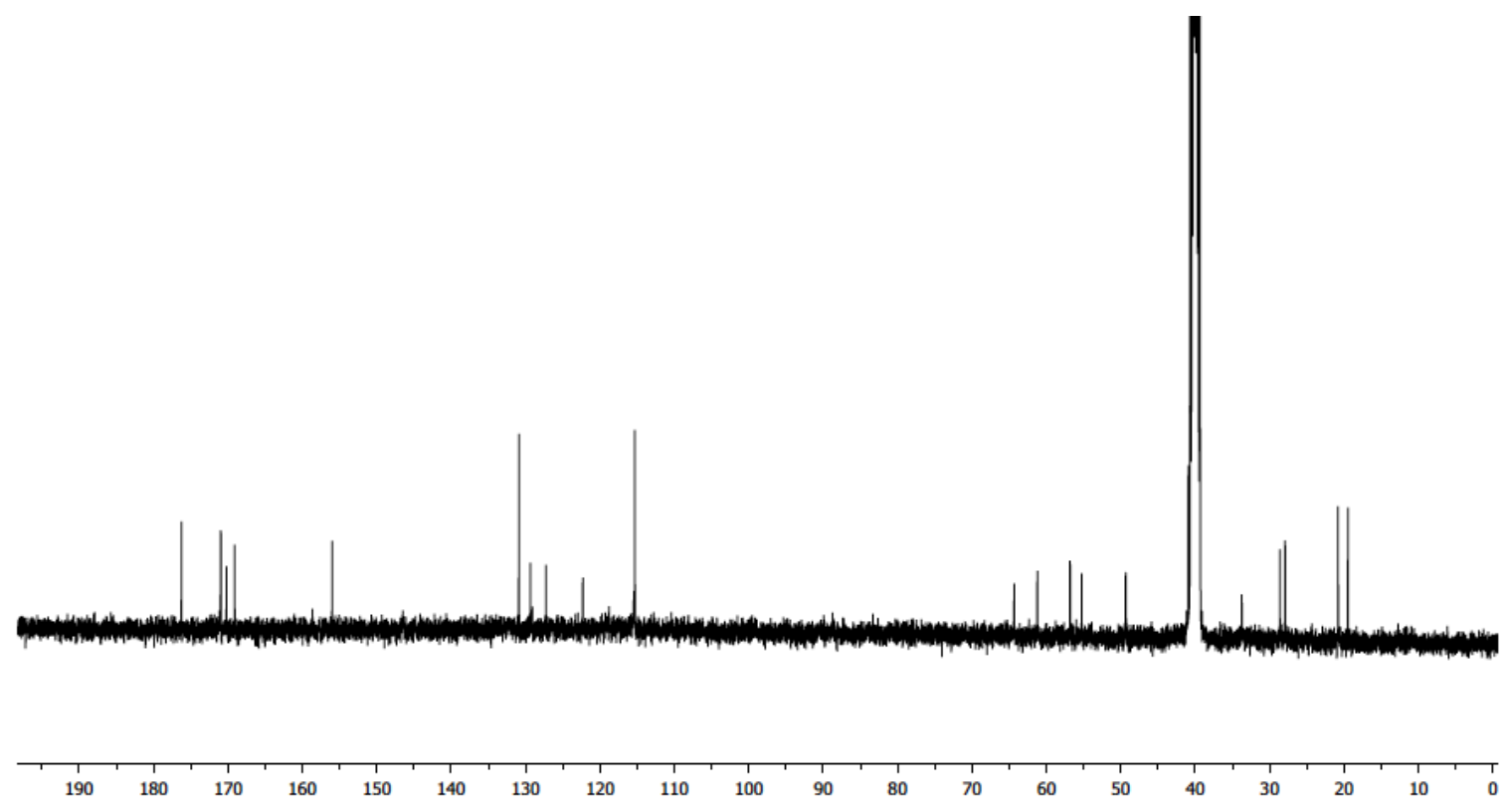
1-((3S,6R,9R)-9-(4-Hydroxybenzyl)-6-(hydroxymethyl)-3-isopropyl-2,5,8,11-

tetraoxo-2,3,4,5,6,7,8,9,10,11-decahydro-1H-

benzo[k][1,4,7,10]tetraazacyclotridecin-13-yl)piperidine-4-carboxylic acid (DDL1ysv)<smiles>CC(C)[C@H]1NC(=O)[C@H](CO)NC(=O)[C@H](Cc2ccc(O)cc2)NC(=O)c2cc(N3CCC(C(=O)O)CC3)ccc2NC1=O</smiles>

${ }^{1} \mathrm{H}$ NMR

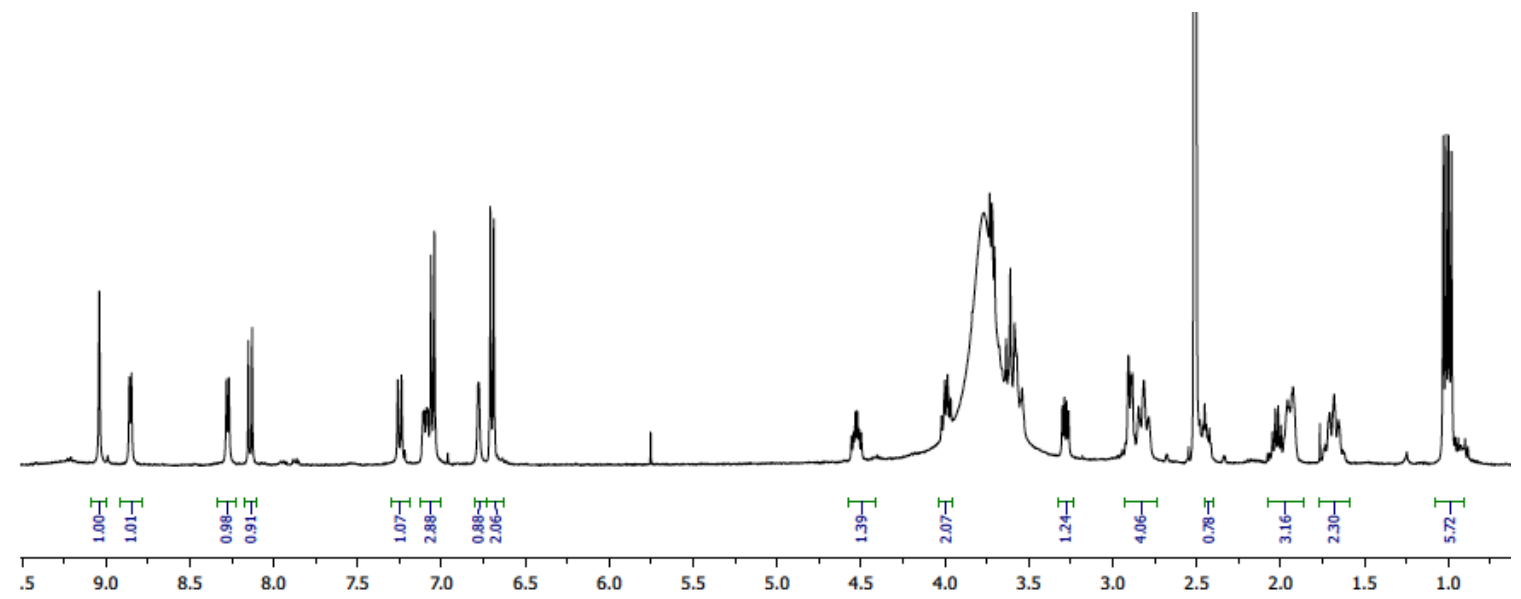


${ }^{13}$ C NMR
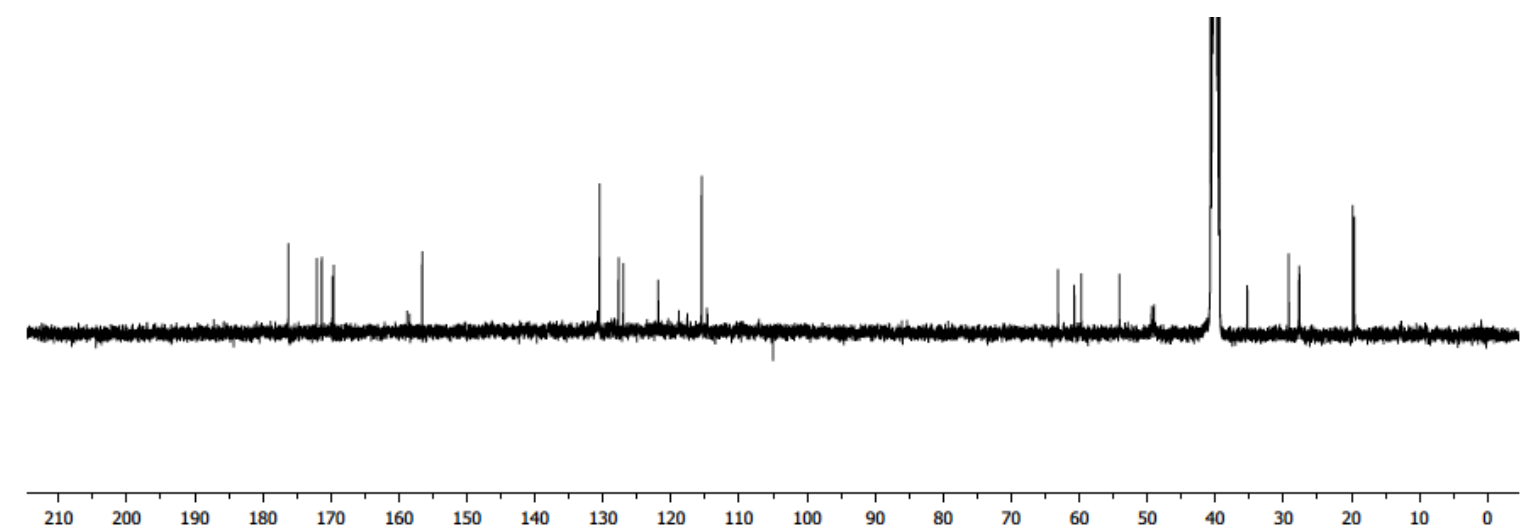

1-((3S,6R,9R)-3-Benzyl-9-(2-carboxyethyl)-6-methyl-2,5,8,11-tetraoxo-

2,3,4,5,6,7,8,9,10,11-decahydro-1H-benzo[k][1,4,7,10]tetraazacyclotridecin-13-

yl)piperidine-4-carboxylic acid (DDL-1eaf)<smiles>CC(C)C(=O)N[C@@H](Cc1ccccc1)C(=O)Nc1ccc(N2CCC(C(=O)O)CC2)cc1C(=O)NC(CCC(=O)O)C(=O)NC(C)C(=O)O</smiles>

S8 
${ }^{1} \mathrm{H}$ NMR

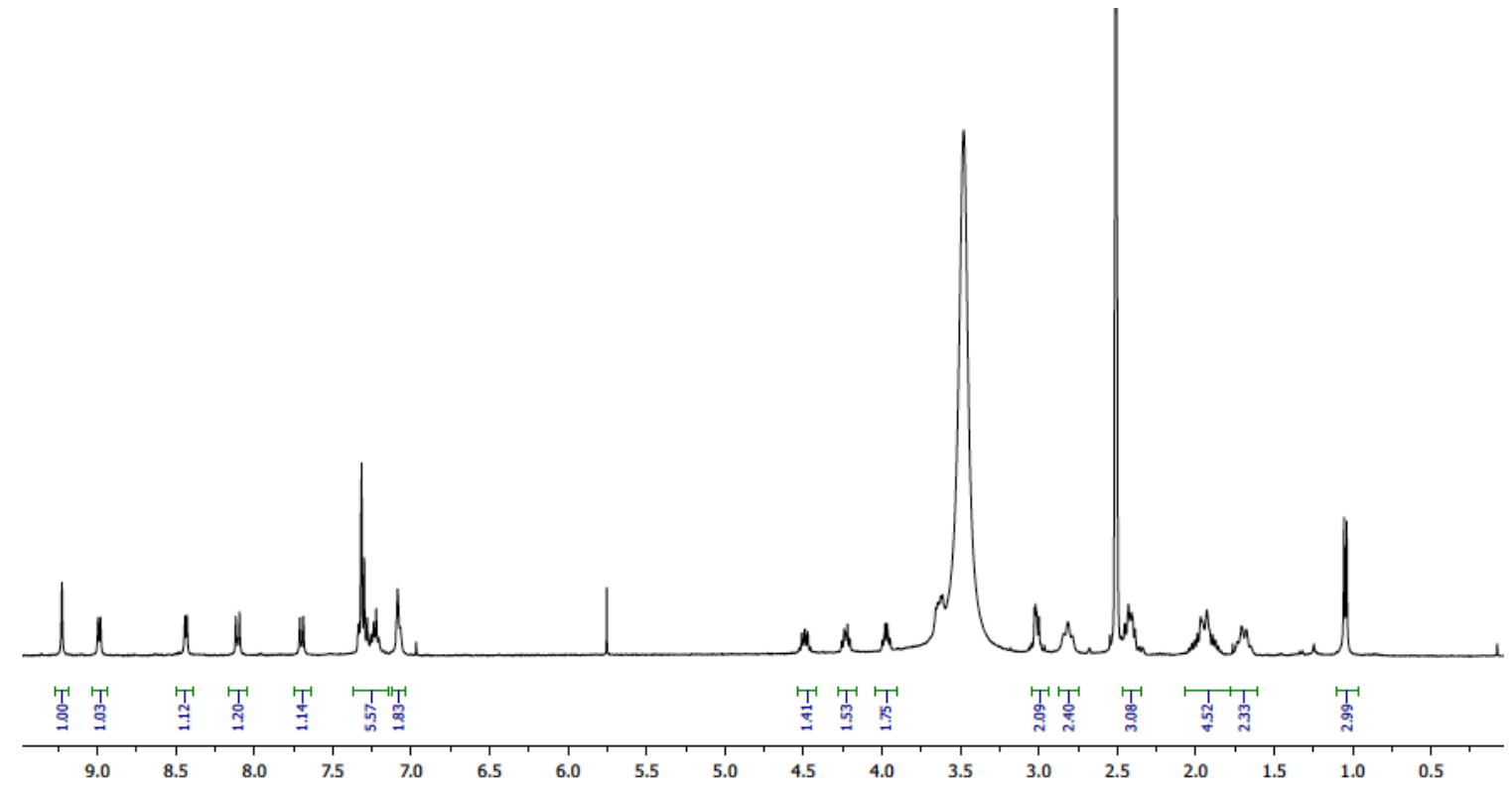

${ }^{13} \mathrm{C}$ NMR
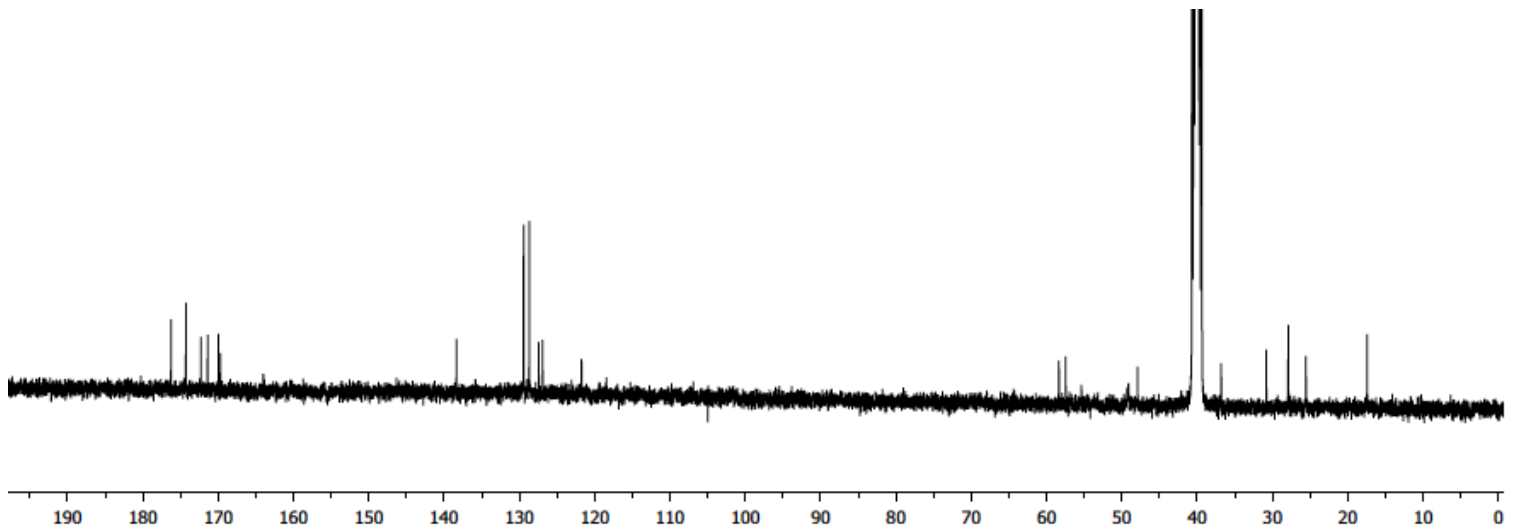
1-((3S,6S,9R)-9-Benzyl-3-(2-carboxyethyl)-6-methyl-2,5,8,11-tetraoxo-

2,3,4,5,6,7,8,9,10,11-decahydro-1H-benzo[k][1,4,7,10]tetraazacyclotridecin-13yl)piperidine-4-carboxylic acid (DLL-1fae)<smiles>C[C@H]1NC(=O)[C@H](Cc2ccccc2)NC(=O)c2cc(N3CCC(C(=O)O)CC3)ccc2NC(=O)[C@H](CCC(=O)O)NC1=O</smiles>

${ }^{1} \mathrm{H}$ NMR

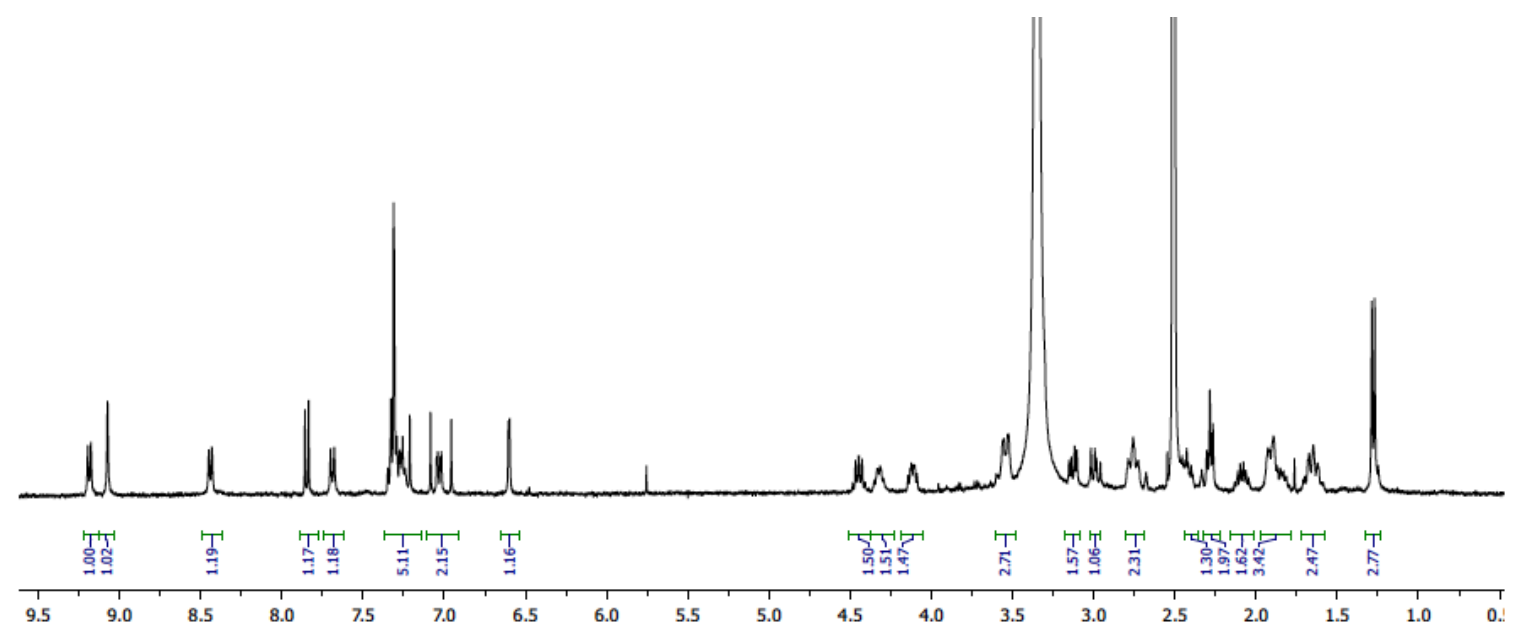




\section{${ }^{13} \mathrm{C}$ NMR}

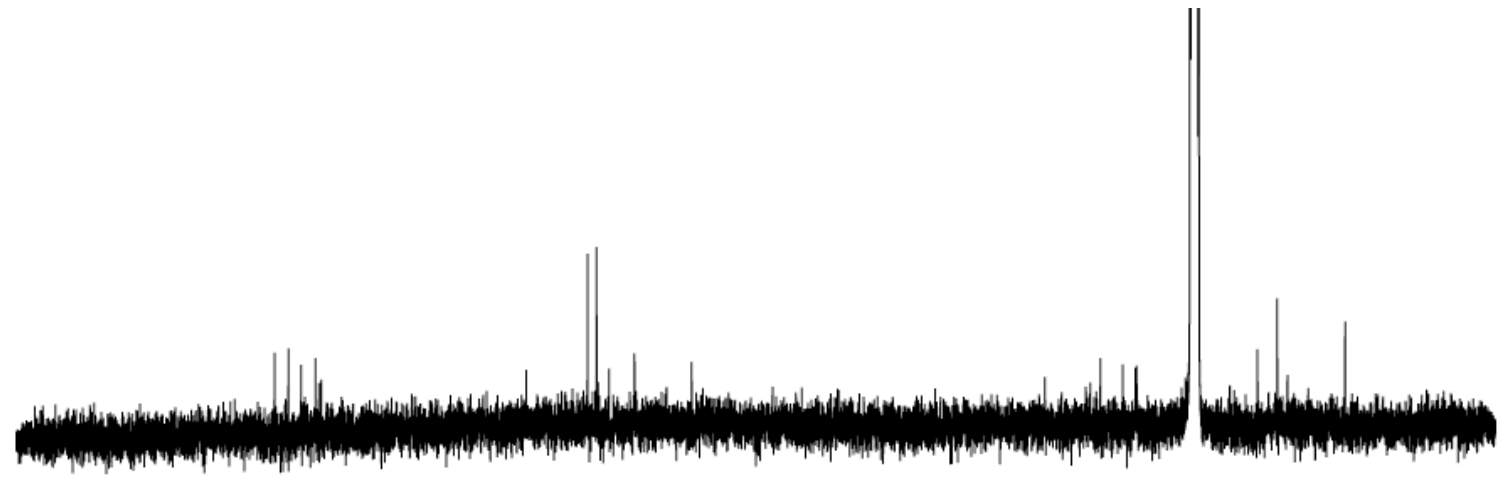

\begin{tabular}{llllllllllllllllllllllllllllll}
\hline 210 & 200 & 190 & 180 & 170 & 160 & 150 & 140 & 130 & 120 & 110 & 100 & 90 & 80 & 70 & 60 & 50 & 40 & 30 & 20 & 10 & 0
\end{tabular}


1-((3S,6S,9S)-3-(((Acetamidomethyl)thio)methyl)-9-methyl-2,5,8,11-tetraoxo-6(3-(3-((2,2,4,6,7-pentamethyl-2,3-dihydrobenzofuran-5-

yl)sulfonyl)guanidino)propyl)-2,3,4,5,6,7,8,9,10,11-decahydro-1H-

benzo[k][1,4,7,10]tetraazacyclotridecin-13-yl)piperidine-4-carboxylic acid (LLD1 ar'c')

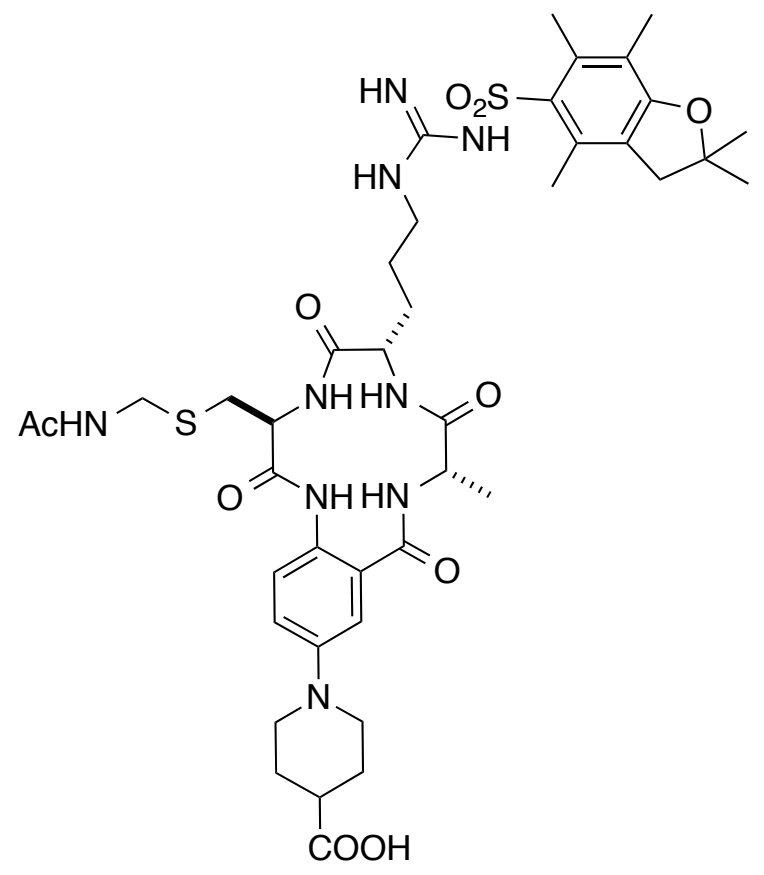


${ }^{1} \mathrm{H}$ NMR

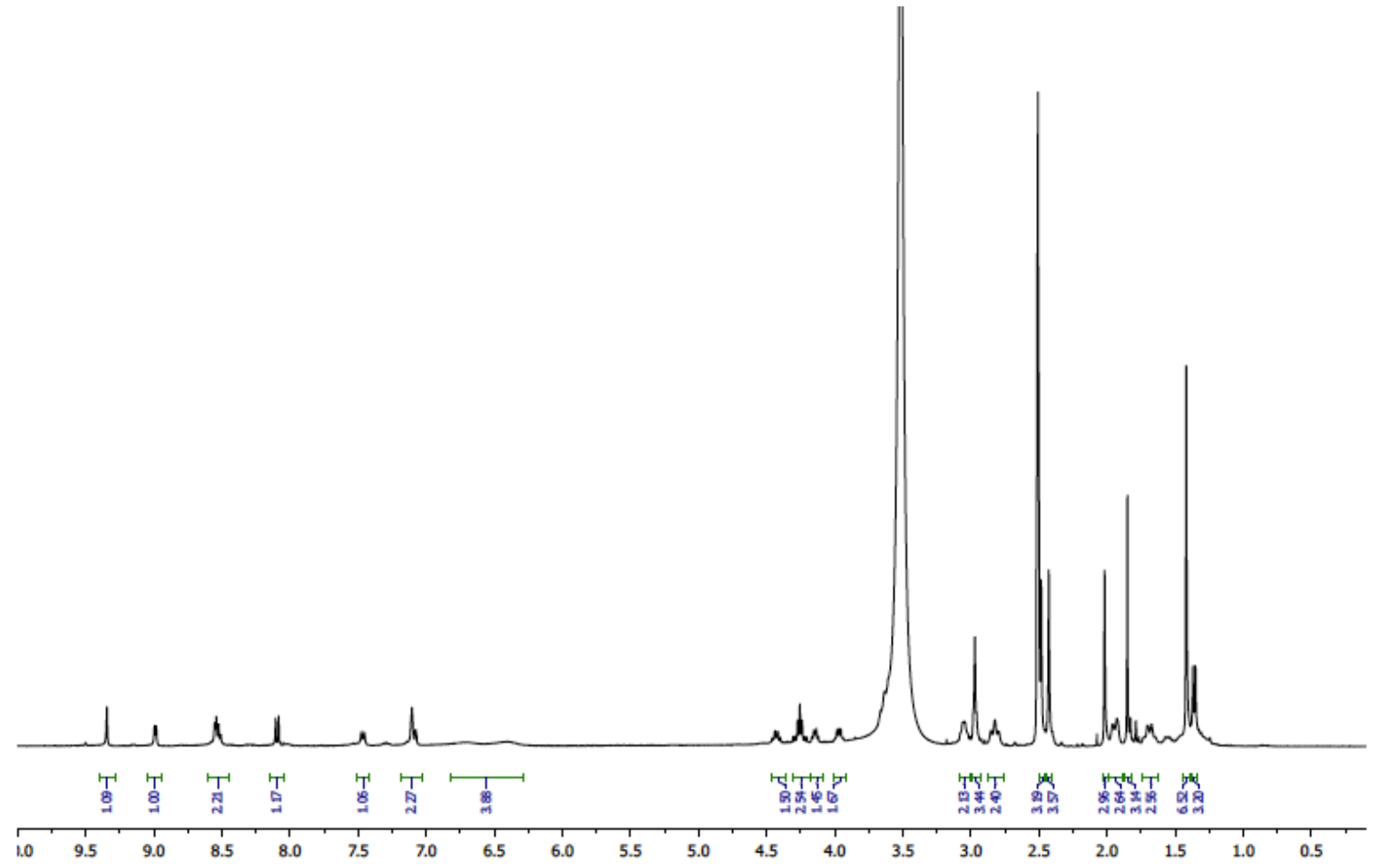

${ }^{13} \mathrm{C}$ NMR

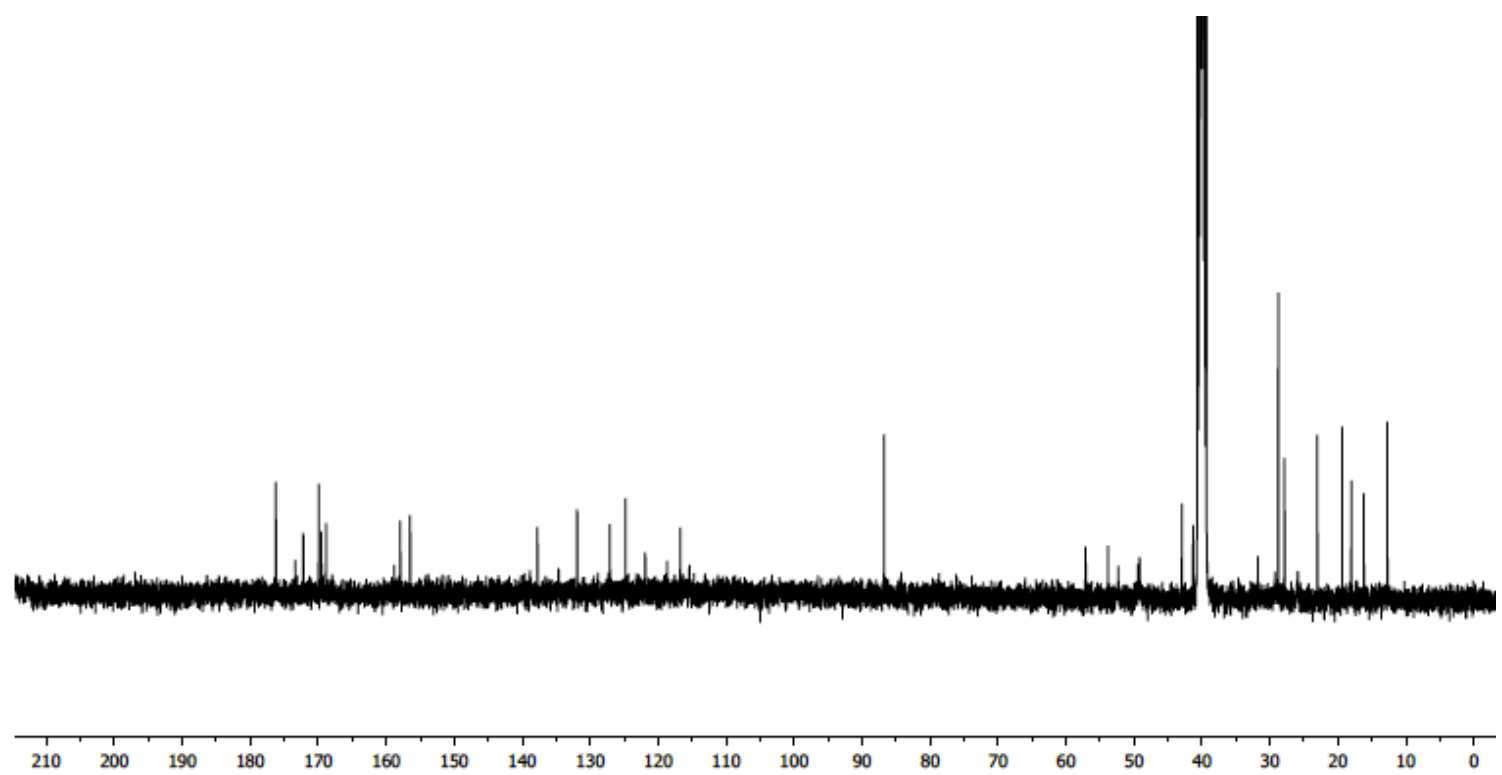


1-((3R,6R,9R)-3-(((Acetamidomethyl)thio)methyl)-6-(3-(tert-butoxy)-3-oxopropyl)2,5,8,11-tetraoxo-9-((1-trityl-1H-imidazol-4-yl)methyl)-2,3,4,5,6,7,8,9,10,11decahydro-1 $H$-benzo[ $k][1,4,7,10]$ tetraazacyclotridecin-13-yl)piperidine-4carboxylic acid (DDL-1h'e'c')

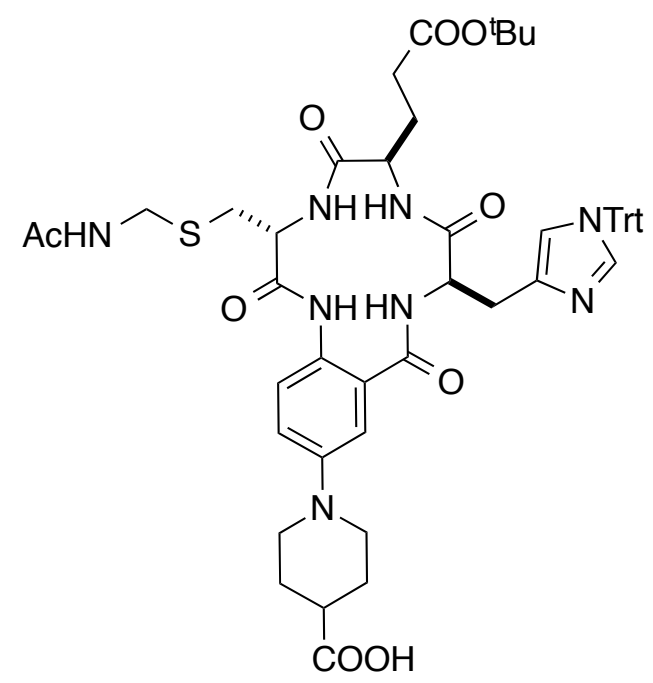

${ }^{1} \mathrm{H}$ NMR

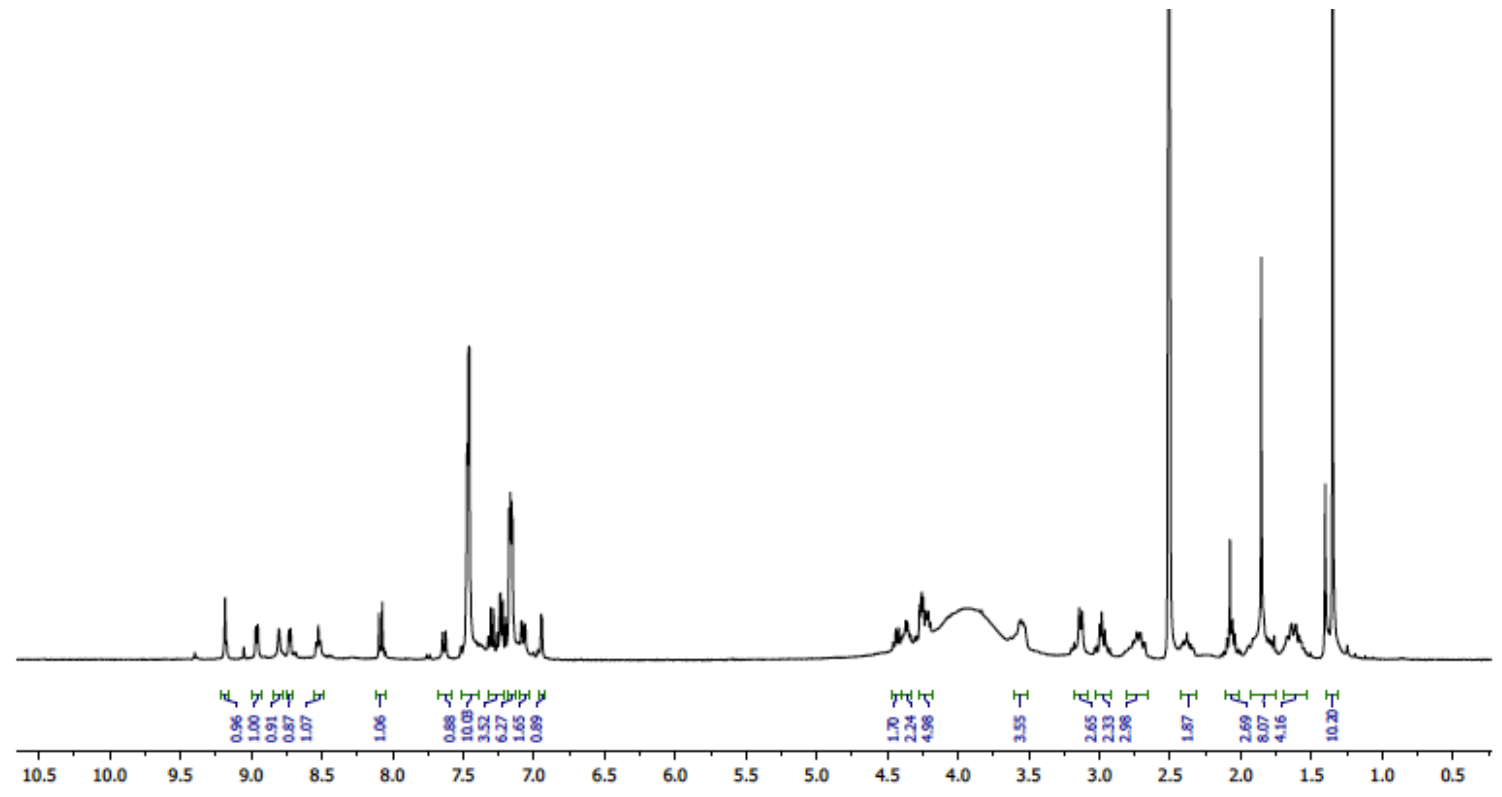




\section{${ }^{13} \mathrm{C}$ NMR}

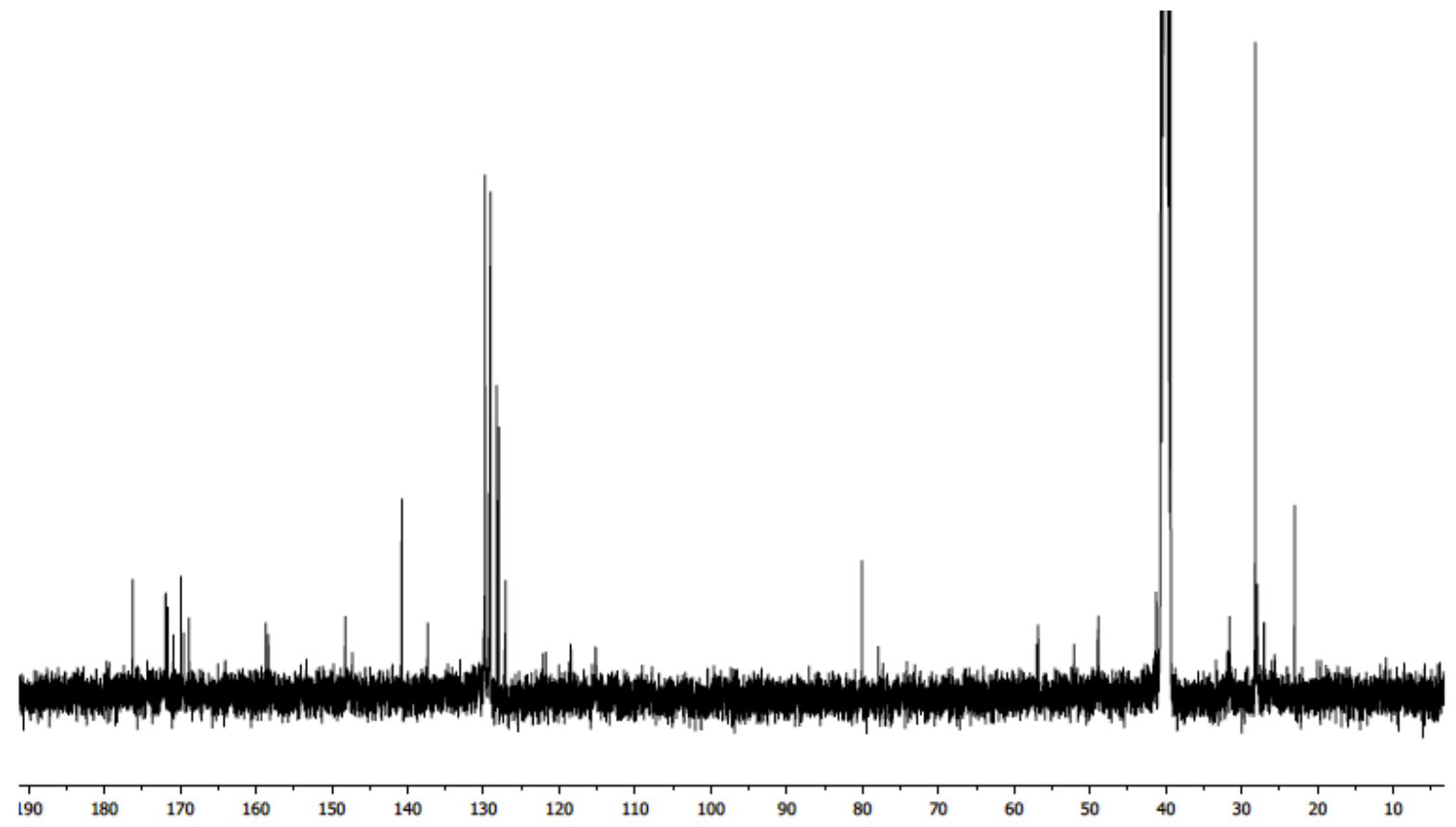




\section{B. Optimization of the Synthesis of Linear Peptides}

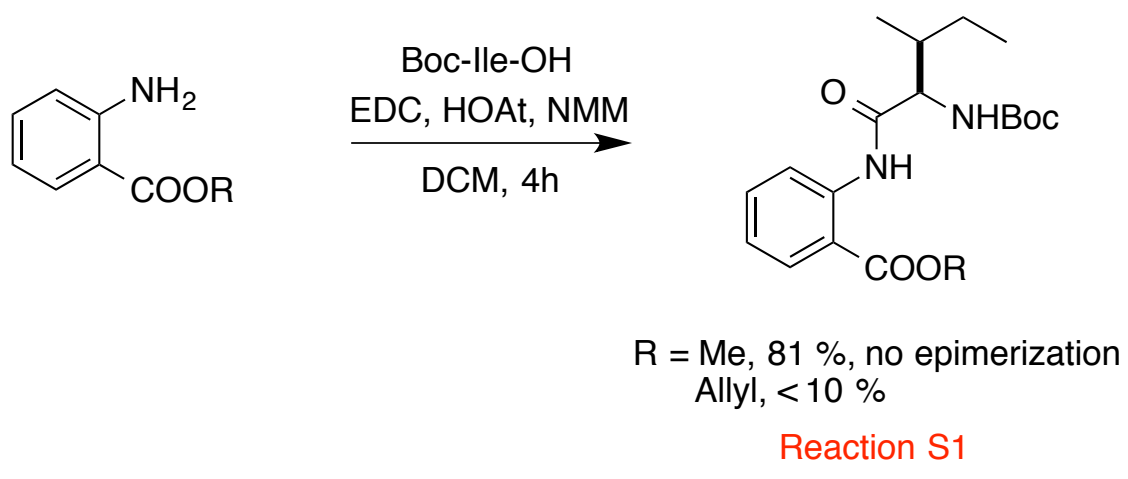

Table S1: Selected Entries for the Optimization of On-bead Methyl Ester Hydrolysis.

$$
\text { B } \underset{\text { (ii) } 20 \%\left(\mathrm{CF}_{3}\right)_{2} \mathrm{CHOH}, \mathrm{CH}_{2} \mathrm{Cl}_{2}, 30 \mathrm{~min}}{\stackrel{\text { (i) base, additive, solvent, time }}{\mathrm{HPLC} \text { analysis }}}
$$

\begin{tabular}{|c|c|c|c|c|c|}
\hline entry & $\begin{array}{c}\text { base } \\
\text { (concentration/M) }\end{array}$ & solvent (ratio) & time $(\mathrm{h})$ & PTR & $\begin{array}{c}\text { conversion } \\
(\%)\end{array}$ \\
\hline 1 & $\mathrm{LiOH}(0.1)$ & $\mathrm{THF} / \mathrm{H}_{2} \mathrm{O}(5: 1)$ & 12 & - & 40 \\
\hline 2 & $\mathrm{LiOH}(0.1)^{a}$ & $\mathrm{THF} / \mathrm{H}_{2} \mathrm{O}(5: 1)$ & 12 & - & 72 \\
\hline 3 & $\mathrm{LiOH}(0.2)$ & $\mathrm{THF} / \mathrm{H}_{2} \mathrm{O}(5: 1)$ & 12 & - & 30 \\
\hline 4 & $\mathrm{KOH}(0.2)$ & $\mathrm{THF} / \mathrm{H}_{2} \mathrm{O}(10: 1)$ & 12 & - & 15 \\
\hline 5 & $\mathrm{LiOH}(0.1)$ & $\mathrm{THF} / \mathrm{H}_{2} \mathrm{O}(2: 1)$ & 12 & - & 8 \\
\hline 6 & $\mathrm{LiOH}(0.1)$ & $\begin{array}{c}\text { THF/MeOH } \\
(5: 1)\end{array}$ & 12 & - & 80 \\
\hline 7 & $\mathrm{LiOH}(0.1)$ & $\mathrm{THF} / \mathrm{H}_{2} \mathrm{O}(5: 1)$ & 1 & - & 6 \\
\hline 8 & $\mathrm{LiOH}(0.1)$ & $\mathrm{THF} / \mathrm{H}_{2} \mathrm{O}(5: 1)$ & 12 & ${ }^{\mathrm{n}} \mathrm{Bu}_{4} \mathrm{NBr}$ & $>95$ \\
\hline 9 & LiOH (0.1) & $\mathrm{THF} / \mathrm{H}_{2} \mathrm{O}(5: 1)$ & 1 & ${ }^{n} \mathrm{Bu}_{4} \mathrm{NBr}$ & $>95$ \\
\hline 10 & $\mathrm{LiOH}(0.1)$ & $\mathrm{THF} / \mathrm{H}_{2} \mathrm{O}(5: 1)$ & 1 & $\mathrm{Et}_{4} \mathrm{NBr}$ & 25 \\
\hline 11 & $\mathrm{LiOH}(0.1)$ & $\mathrm{THF} / \mathrm{H}_{2} \mathrm{O}(5: 1)$ & 1 & $\mathrm{BnNEt}_{3} \mathrm{Cl}$ & 42 \\
\hline 12 & $\mathrm{LiOH}(0.1)$ & $\mathrm{THF} / \mathrm{H}_{2} \mathrm{O}(5: 1)$ & 1 & $\mathrm{Hex}_{4} \mathrm{NBr}$ & 89 \\
\hline 13 & $\mathrm{LiOH}(0.1)$ & $\mathrm{THF} / \mathrm{H}_{2} \mathrm{O}(5: 1)$ & 1 & $\left({ }^{\mathrm{n}} \mathrm{C}_{16} \mathrm{H}_{33}\right) \mathrm{N}\left(\mathrm{CH}_{3}\right)_{3} \mathrm{Br}$ & 65 \\
\hline 14 & $\mathrm{LiOH}(0.1)$ & $\mathrm{THF} / \mathrm{H}_{2} \mathrm{O}(5: 1)$ & 1 & $\mathrm{Ph}_{4} \mathrm{PBr}$ & 5 \\
\hline 15 & $\mathrm{LiOH}(0.1)$ & $\mathrm{THF} / \mathrm{H}_{2} \mathrm{O}(5: 1)$ & 1 & $\mathrm{Ph}_{3} \mathrm{PEtBr}$ & 6 \\
\hline $16^{\mathrm{b}}$ & $\mathrm{LiOH}(0.1)$ & $\mathrm{THF} / \mathrm{H}_{2} \mathrm{O}(5: 1)$ & 1 & ${ }^{n} \mathrm{Bu}_{4} \mathrm{NBr}$ & 55 \\
\hline $17^{\mathrm{c}}$ & TBAOH $(0.1)$ & $\mathrm{THF} / \mathrm{H}_{2} \mathrm{O}(5: 1)$ & 1 & & $>95$ \\
\hline
\end{tabular}

a. $50^{\circ} \mathrm{C}$, loss of peptide observed by HPLC;

b. 1 equiv. of ${ }^{\mathrm{n}} \mathrm{Bu}_{4} \mathrm{NBr}$;

c. significant loss of peptide by HPLC. 


\section{Optimization of On-bead Cyclization}

Table S2: Selected Entries for the Optimization of On-bead Cyclization. ${ }^{\text {a }}$
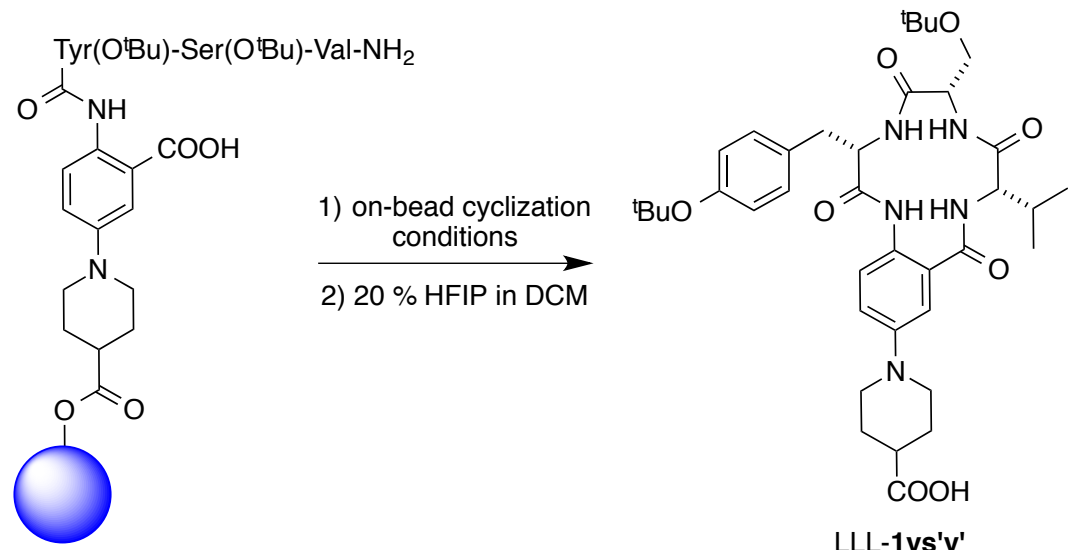

LLL-1vs'y'

\begin{tabular}{cccccc}
\hline entry & activating reagent & nucleophile & base & solvent & yield (\%) \\
\hline 1 & EDC & HOAt & NMM & DMF & 26 \\
2 & PyBOP & HOAt & NMM & DMF & 28 \\
3 & PyBOP & HOAt & DIPEA & DMF & 14 \\
4 & DIC & HOAt & NMM & DMF & 40 \\
5 & DIC & HOAt & NMM & DCM & 15 \\
6 & DIC & HOAt & NMM & NMP & 0 \\
7 & DCC & HOAt & NMM & DMF & 59 \\
8 & DCC & HOAt & NMM & DCM & 11 \\
9 & DCC & HOAt & NMM & NMP & 0 \\
10 & DEPBT & HOAt & NMM & DMF & 5 \\
11 & DCC & - & NMM & DMF & 0 \\
12 & DCC & HOBt & NMM & DMF & 33 \\
13 & DCC & HOAt & DIPEA & DMF & 23 \\
14 & DCC & HOAt & $2,6-l$ lutidine & DMF & 36 \\
$15^{\text {b }}$ & DCC & HOAt & NMM & DMF & 30 \\
$16^{\text {c }}$ & DCC & HOAt & NMM & DMF & 19 \\
$17^{\text {d }}$ & DCC & HOAt & NMM & DMF & 72 \\
$18^{\mathrm{e}}$ & DCC & HOAt & NMM & DMF & $\mathbf{8 1}$ \\
\hline
\end{tabular}

a. Generally, the cyclization reaction was carried out with 3 equiv. of activating reagent, 3 equiv. of nucleophile and 6 equiv. of base at $0.06 \mathrm{M}$ concentration in the indicated solvent. The initial loading is $0.2 \mathrm{mmol} / \mathrm{g}$ to reduce the dimerization and oligomerization;

b. $0.4 \mathrm{mmol} / \mathrm{g}$ loading was used instead of $0.2 \mathrm{mmol} / \mathrm{g}$;

c. $12 \mathrm{~h}$;

d. $72 \mathrm{~h}$;

e. Staged cyclization method. 
Side-product from the on-bead cyclization with HATU:

1-(3-carboxy-4-((5S,8S, 11S)-3-(Dimethylamino)-11-(4-hydroxybenzyl)-8-

(hydroxymethyl)-5-isopropyl-2-methyl-6,9-dioxo-2,4,7,10-tetraazadodec-3-en-12amido)phenyl)piperidine-4-carboxylic acid<smiles>CC(=O)N=C(N=C(C)C(C(=O)NC(CO)C(=O)N[C@@H](Cc1ccc(O)cc1)C(=O)Nc1ccc(N2CCC(C(=O)O)CC2)cc1C(=O)O)C(C)C)C(C)C</smiles>

${ }^{1} \mathrm{H}$ NMR

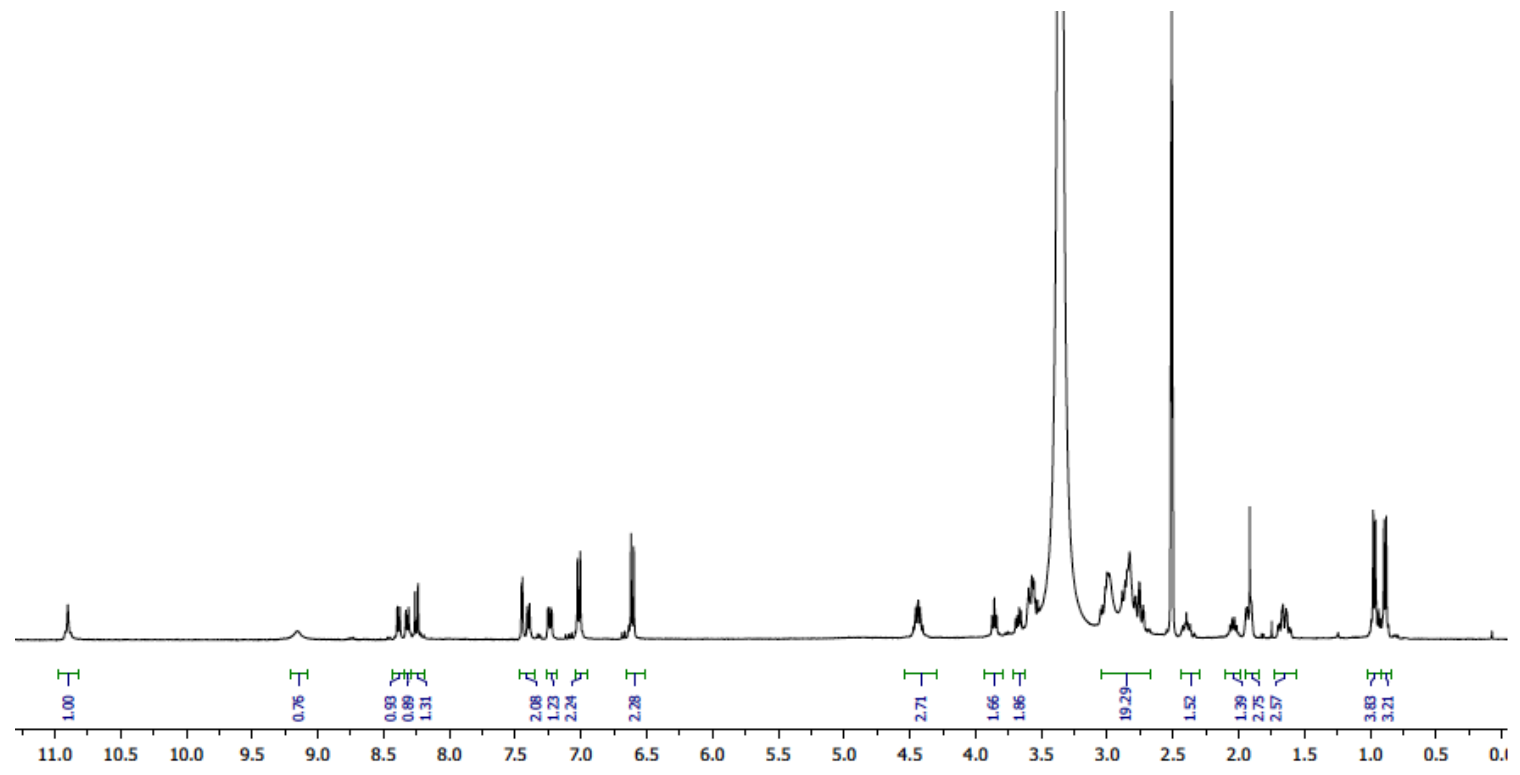


${ }^{13} \mathrm{C}$ NMR
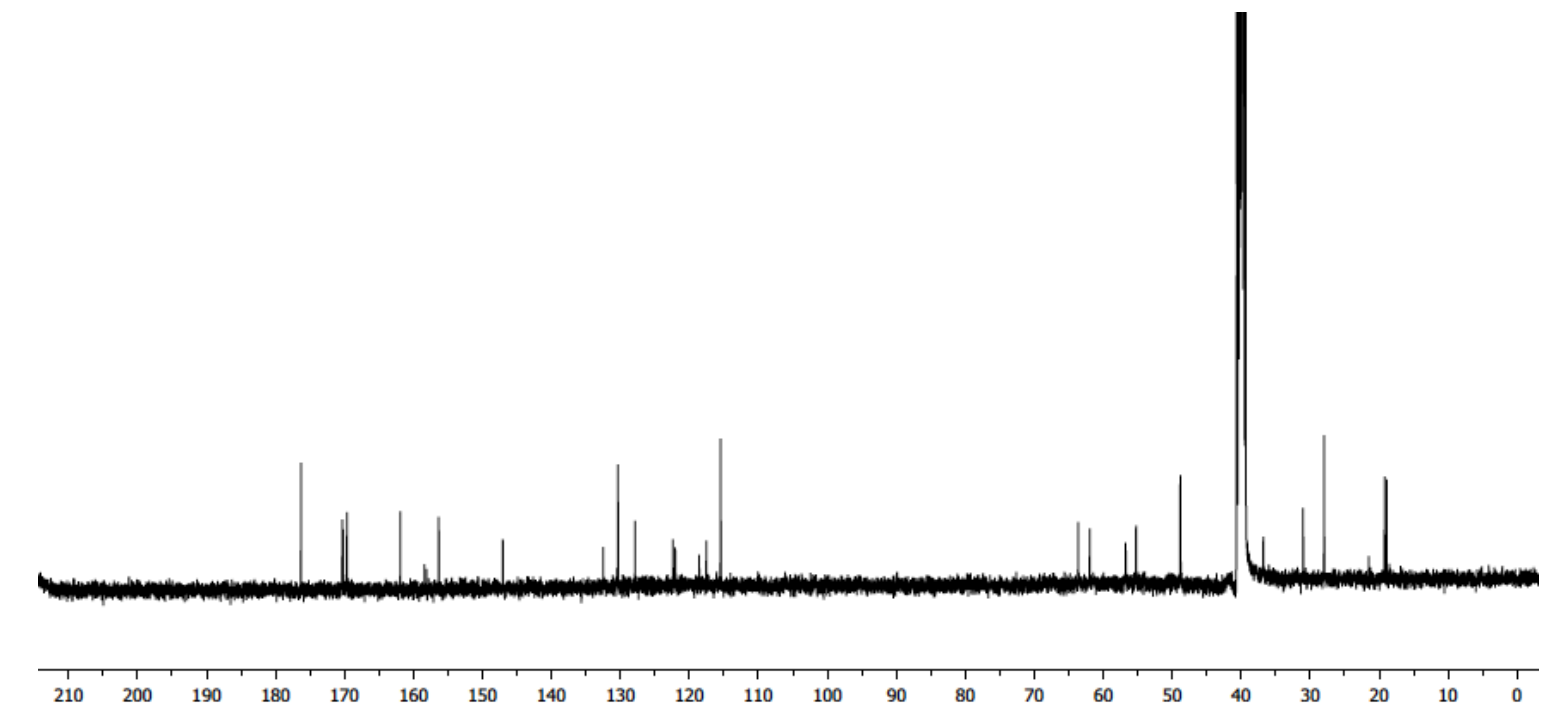


\section{HPLC Traces For Crude Cyclic Peptide Products Cleaved From The Resin}

After cyclization, the cyclic peptide products were cleaved from a small amount of resin with Cleavage From Solid Support Method 1 in $\mathbf{C}$ and analyzed by reversed-phase HPLC.
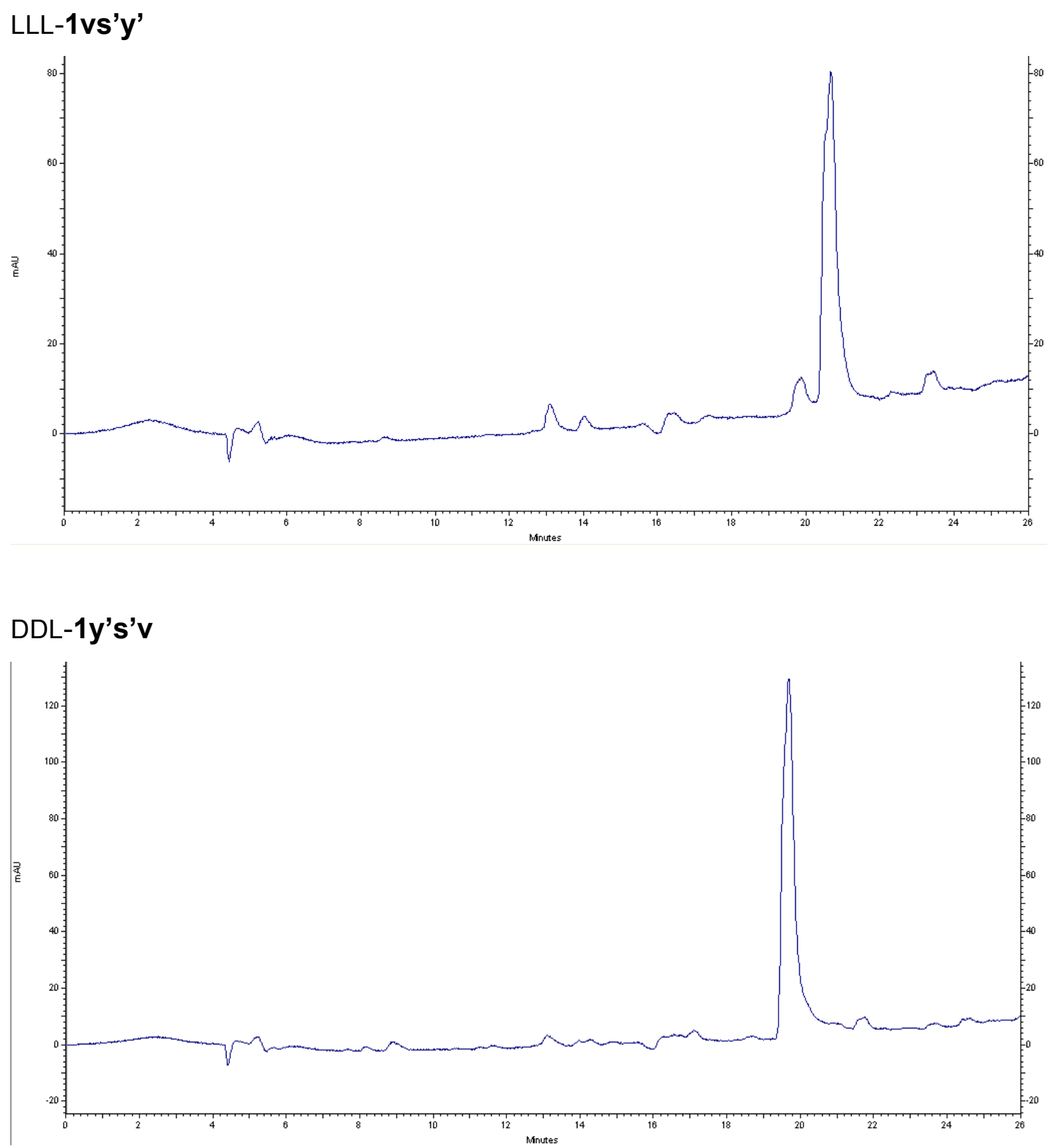

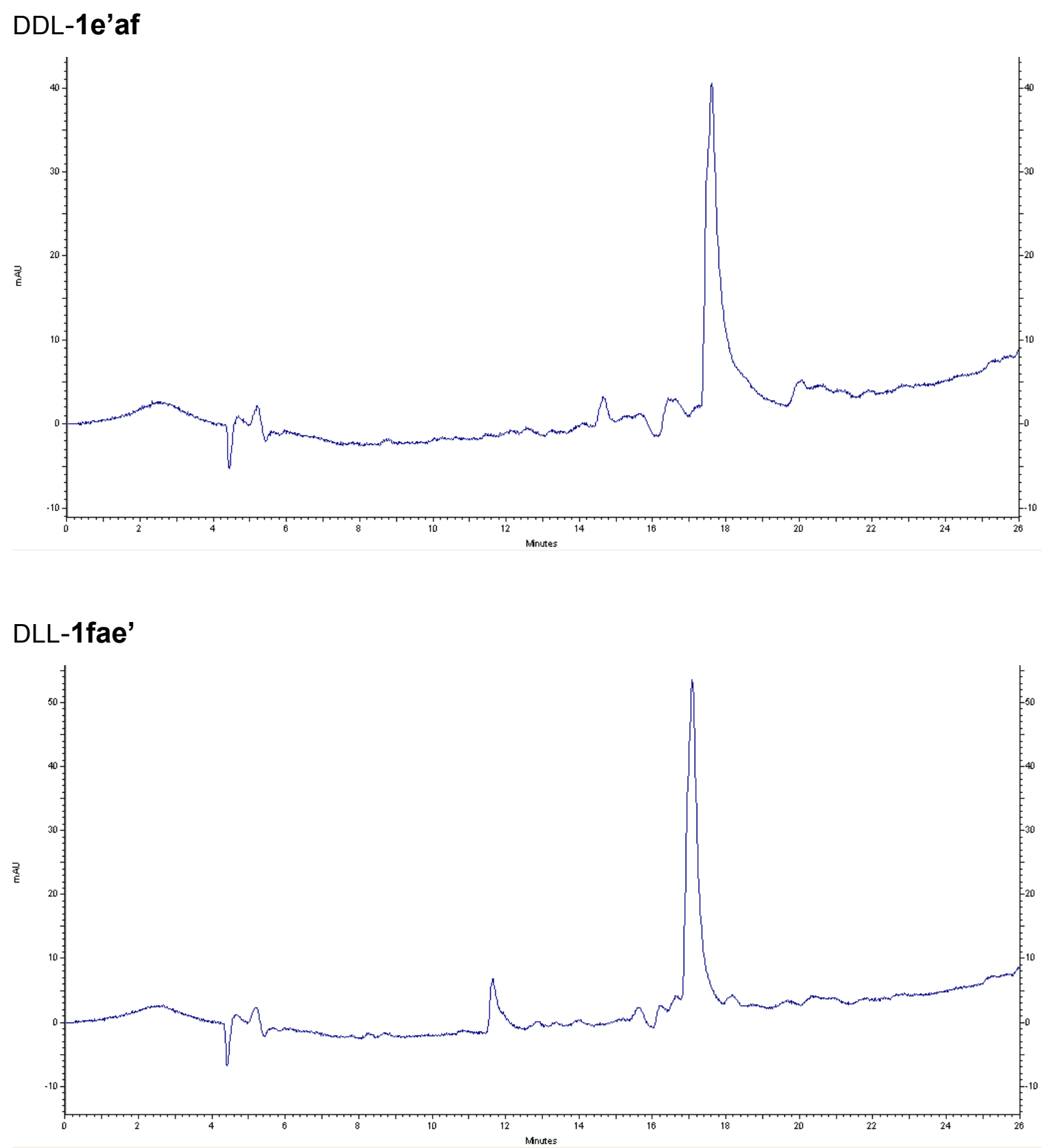

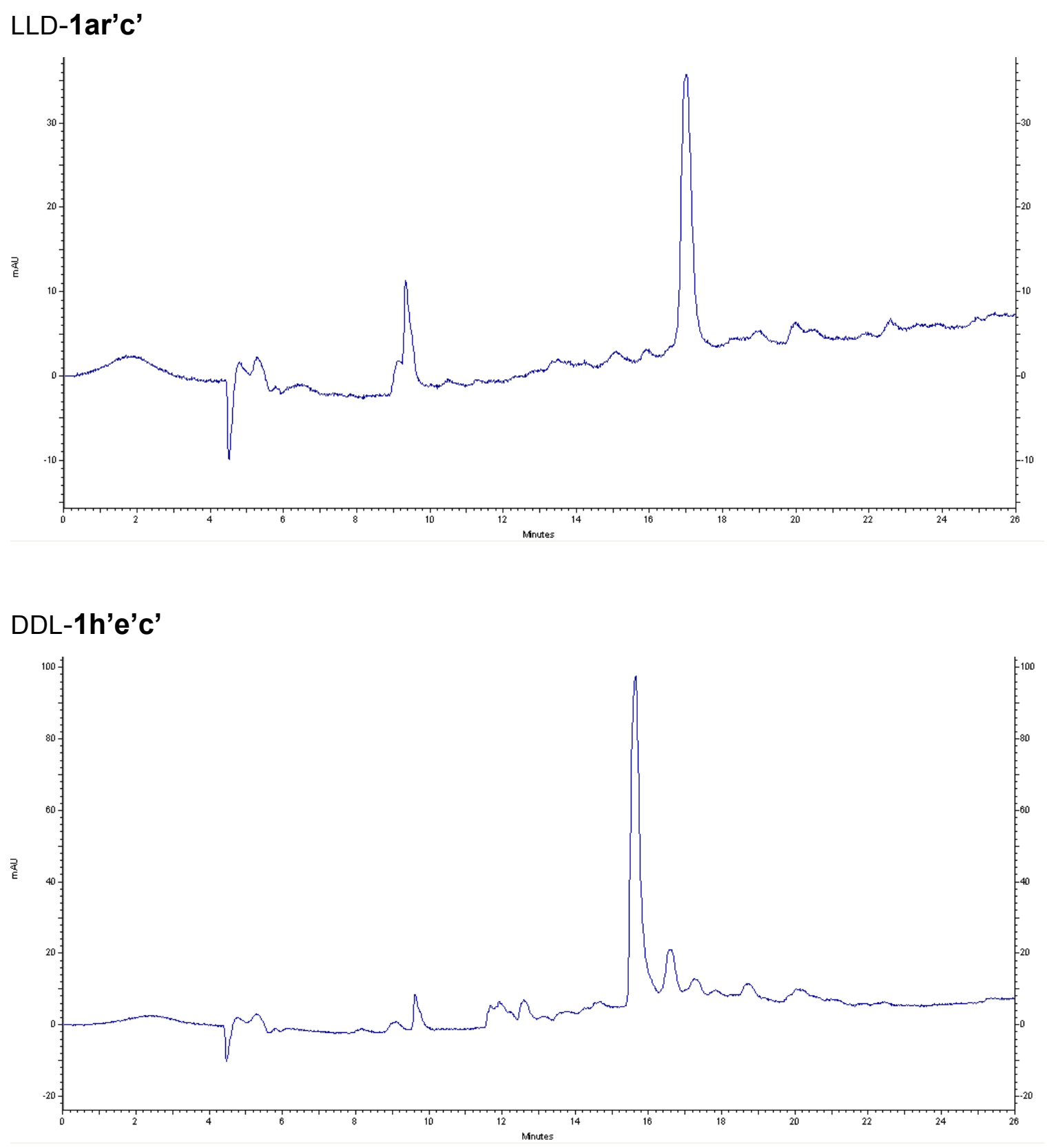